\title{
Safety on judo children: methodology and results
}

\section{Opinion}

Biomechanics, Children Safety; Judo Throws, Elastocaloric Effect, Impact Biomechanics, Crash Test Methodology, Thermo mechanics of materials. The main problem against the acceptance of judo for children as sport, in the families, is the "strange" position that some medicine doctors have respect to judo. Many doctors although they have not firsthand experience of judo, describe it as a sport unsuitable for children, often expressing themselves so broadly negative in some books or even via web.

Theoretically speaking falls derived by Judo throwing techniques, could be potentially dangerous, especially for kids, if poorly managed. Obviously all judo people knows that good judo is safe for children, and how doctors affirmations are generalist and negative, but the "truth" is based only on many personal experiences, not supported by scientific evidence worldwide accepted. A lot of researches were focalized on traumas or injuries taking place in judo, both during training and competition, from these papers, you know, paradoxically, that training has a higher content of incidents against competition.

However never a totally complete Scientific Research was performed to support the danger or the harmlessness of judo for kids, especially with regard to potential traumas deriving by falls due to throwing techniques. The goal of this Research is to define and apply a scientific methodology to evaluate the hazard in falls by judo throws for children during training.

By organizing the research on the basis of Safety Analysis, there are at first defined and experimentally evaluated for fifteen among boys and girls:

1. Five throws as example of different falls and flight time

2. The flight time for these five throws

3. The maximum impact forces and velocities for the five throws

4. The contact surfaces of bodies on the Tatami for each of the five different throws.

5. The Elastocaloric effect to evaluate the energy absorption by Tatami Materials.

6. The maximum Strain on the Tatami.

7. The impact reaction Stress on the children bodies.

After valuated the mechanic of falls on the basis of Principle of simultaneous "Actions" and the property of adding together two vectors. Is performed the evaluation of contact body surfaces on the Tatami, by a Japanese AVIO Thermal Camera.

The next step is to connect the impact biomechanics with the potential traumas.

The only worldwide accepted methodology both from Medical and Engineering people is the Crash test Methodology. Along with
Volume I Issue 2 - 2017

\author{
Attilio Sacripanti,' Tania de Blasis² \\ 'EJU Scientific Commission, FIJLKAM, Italy \\ ${ }^{2}$ University of Tor Vergata, FIJLKAM, Italy
}

Correspondence: Attilio Sacripanti, EJU Scientific Commission, Italy, Email attilio.sacripanti@uniroma2.it

Received: May 29, 2017 | Published: May 31, 2017

the appropriate changes in the specifications of the "Crash Test Methodology" there are defined and evaluated:

1. A "judo boy Dummy", like "Reference Man" for medical People in radio-protection to apply safety criteria used in crash test.

2. Both: Thoracic Trauma Index and Compression Index

3. The Head Injury Criterion

4. The probability of skull fracture (if any) applying risk analysis.

Connecting in this way, the mechanical results with the resulting physiological hazard connected to Judo throwing techniques, using the "Crash Test Methodology" it is proved that, correct falls of judo throws are safe for "judo boy Dummy", on IJF approved Tatami and for logical extension they are safe, also for judo children people.

The last two troubles that our analysis has singled out about still judo throwing techniques training for kids are:

The wrong combination of kids during training and the potential long term trauma that have for organ target both Liver and Spleen-

These unevaluated problems are present in kids training, in such delicate issues a Digital Assistant named (Hazard Training Sentinel) that is able both to inform if connection between strong child and a delicate one is dangerous and to alert if cumulative stress for spleen and liver could be dangerous for a specific boy, in such situation the software asks to stop children from fall for a necessary time period.

This App/Software has been prepared to help teachers to manage in optimal way this specific aspect of their important and delicate work.

\section{Acknowledgements}

None.

\section{Conflict of interest}

Author declares there is no conflict of interest in publishing the article. 